\title{
The Apolipoprotein Gene and Recovery from Brain Injury among Extremely Preterm Infants
}

\author{
James A. Blackman ${ }^{\mathrm{a}}$ e Heather Gordish-Dressman ${ }^{d}$ Yondge Bao ${ }^{\mathrm{b}}$ \\ Julie A. Matsumoto ${ }^{c}$ Robert A. Sinkin ${ }^{a}$ \\ Departments of a Pediatrics, ${ }^{b}$ Microbiology, Immunology and Cancer Biology and ${ }^{\mathrm{C}}$ Radiology and Medical Imaging, \\ University of Virginia, Charlottesville, Va., ${ }^{d}$ Center for Genetic Medicine Research, Children's National Medical \\ Center, George Washington University, Washington, D.C., and e Cerebral Palsy International Research Foundation, \\ Princeton Junction, N.J., USA
}

\section{Key Words}

Apolipoprotein E. Brain injury · Genetics

\begin{abstract}
Background: Extremely preterm infants have an increased risk of brain injury and, consequently, are more likely to exhibit signs of motor, cognitive or behavioral impairment. Various factors, including genetic, may influence how the brain responds to an injury, ranging from no to complete recovery. The apolipoprotein E (APOE) gene codes for a protein in the brain involved in maintenance and repair of neurons. Objective: To determine whether any of the three APOE alleles are related to improved outcome. Methods: A total of 87 preterm infants with birth weights less than $1,000 \mathrm{~g}$ and no obvious preexisting brain abnormalities were genotyped for the APOE gene; 71 of these were assessed with the Bayley III Scales at a corrected age of 12-15 months. Brain MRI was obtained on a subgroup of 52 infants at term equivalent. Results: No significant relationship was found between the three APOE alleles and developmental outcomes or brain MRI findings. Conclusion: APOE does not appear to be related in a direct way to the developmental sequelae of white or gray matter injury in extremely preterm infants.

๑) 2014 S. Karger AG, Basel
\end{abstract}

\section{Introduction}

Extremely preterm infants have an increased risk of brain injury and, consequently, are more likely to exhibit signs of motor, cognitive or behavioral impairment [1]. Studies have examined the effects of apolipoprotein $\mathrm{E}$ (APOE) genotype on outcomes after brain injury, primarily in adults - rarely in children [2]. The APOE gene has three variants (e2, 3 and 4 ) and encodes the apoE protein involved in maintenance and repair of neurons in the central nervous system. While the presence of the APOE e4 allele is associated with an increased risk for Alzheimer's disease and worse neurological outcome in adults, some studies suggested APOE e4 may be protective in the developing brain of children after brain injury $[3,4]$. The aims of this study were to demonstrate the following: (1) that APOE e4, in contrast to alleles e 2 or e 3 , is associated with better neurodevelopmental outcome at a corrected age of 12-15 months, (2) that APOE e4 has a mitigating effect of white matter injury on development (thus, preventing or lessening the severity of cerebral palsy commonly associated with white matter injury) and (3) that APOE genotype effects vary at different gestational ages and birth weights.

\section{KARGER}

E-Mail karger@karger.com

www.karger.com/neo
(C) 2014 S. Karger AG, Basel

$1661-7800 / 14 / 1053-0227 \$ 39.50 / 0$
James A. Blackman, MD, MPH

Cerebral Palsy International Research Foundation

186 Princeton Hightstown Rd.

Princeton Junction, NJ 08550 (USA)

E-Mail jblackman@cpirf.org 
Table 1. Comparison of Bayley III composite scores with APOE e4 alleles

\begin{tabular}{llllllll}
\hline $\begin{array}{l}\text { Bayley III } \\
\text { subscales }\end{array}$ & \multicolumn{2}{l}{ No e 4} & & & & & \\
\cline { 2 - 3 } & $\mathrm{n}$ & mean \pm SD & & $\mathrm{n}$ & mean \pm SD & & value \\
\hline Cognitive & 46 & $99 \pm 17$ & & 25 & $93 \pm 16$ & 0.12 \\
Language & 46 & $94 \pm 17$ & & 25 & $95 \pm 15$ & 0.94 \\
Motor & 46 & $87 \pm 14$ & & 25 & $89 \pm 17$ & 0.71 \\
Socioemotional & 27 & $103 \pm 21$ & & 18 & $99 \pm 18$ & 0.56 \\
\hline
\end{tabular}

Language was analyzed as squared variable due to right skewness of distribution.

Table 2. Comparison of brain MRI white matter scores with APOE

\begin{tabular}{llllllll}
\hline $\begin{array}{l}\text { MRI } \\
\text { score }\end{array}$ & Genotype & & \multirow{2}{*}{ OR } & $95 \%$ CI & p value & $\begin{array}{l}\mathrm{p} \text { value } \\
\text { for trend }\end{array}$ \\
\cline { 2 - 3 } & no e4 & e4 & & & & & \\
\hline 0 & $15(41.7)$ & $8(50.0)$ & & 1.00 & - & - & \\
1 & $13(36.1)$ & $6(37.5)$ & & 0.86 & $0.24-3.15$ & 0.83 & 0.27 \\
2 & $3(8.3)$ & $2(12.5)$ & & 1.25 & $0.17-9.09$ & 0.83 & \\
3 & $5(13.9)$ & $0(0.0)$ & - & - & & \\
\hline
\end{tabular}

MRI score: 0 = no abnormalities; $4=$ severe abnormalities. Genotype values are expressed as numbers with percentages in parentheses. 4 alleles

periventricular white matter and the extent of any cystic abnormalities, ventricular dilatation or thinning of the corpus callosum.

The Bayley Scales of Infant and Toddler Development III was administered by one of two certified examiners on 71 subjects at a corrected age of 12-15 months. Data were analyzed independently by a genetic epidemiologist at the Children's National Medical Center, Washington, D.C., USA.

The project was originally powered for 120 subjects to detect a mean difference of 11 points in the Bayley Scales. Given the small difference in scores seen in the actual sample, it is likely that additional subjects would not show a difference large enough to be statistically significant.

\section{Results}

The mean birth weight of the sample was $750 \pm 123 \mathrm{~g}$; mean gestational age was $25.2 \pm 1.6$ weeks. A total of $54 \%$ percent were male, and $32 \%$ had at least one APOE e 4 allele; $45 \%$ percent of African-American infants and $27 \%$ of Caucasian infants had at least one e4 allele.

There was no significant relationship between the APOE e4 allele and either Bayley III scores or MRI white matter scores at any gestational age or birth weight (tables $1,2)$. Likewise, no consistent relationship was demonstrated between the e 2 or e 3 alleles and the same outcome measures. However, all 5 infants with the most severe MRI abnormalities (a score of 3) were in the 'no e4' group (table 2).

\section{Discussion}

\section{Methods}

The University of Virginia institutional review board approved this study. APOE genotype was prospectively ascertained by analysis of DNA obtained by buccal swab on 87 infants admitted to the NICU with birth weights less than $1,000 \mathrm{~g}$ and negative screening for intrauterine growth restriction, cerebral dysgenesis or any genetic, sensory or metabolic abnormality associated with brain abnormalities; 10 additional subjects were added after NICU discharge with the same eligibility criteria. Single nucleotide polymorphisms genotyping by the TaqMan allelic discrimination method was employed to determine the allele compositions of APOE Cd112 (rs429358) and Cd158 (rs7412). All the genotyping was performed in triplicate on an Applied Biosystems $7900 \mathrm{HT}$ Sequence Detection System (Life Technologies Corp., Carlsbad, Calif., USA). Data failing a consistency check at a confidence level of $95 \%$ were subjected to repeat. Samples failing even after repeat were removed from further analyses.

A standard brain MRI was obtained at term equivalent on 52 subjects and blindly scored by one neuroradiologist according to the criteria of Woodward et al. [5]. White matter abnormality was graded according to five scales, which assessed the nature and extent of white matter signal abnormality, the loss in the volume of
Individual genetic variation may account for clinical differences in outcomes for premature infants who exhibit white matter abnormalities. Lien et al. [6] recently demonstrated a higher prevalence of the APOE e4 allele among children with cerebral palsy who had epilepsy, were receiving gastrostomy tube feedings and had more severe fine motor impairment, suggesting an adverse effect of the APOE e4 genotype on the developing brain after injury.

We found no statistically significant relationships between the APOE genotype and various short-term developmental outcome measures. The finding of all 5 infants with the severest white matter abnormalities in the 'no E4' group suggests a possible protective effect of the e4 allele.

White matter abnormalities commonly observed in preterm infants are highly associated with cerebral palsy [7]. Cerebral palsy is a diverse condition affecting body movement, muscle tone and coordination. It is likely that the type, location, extent and timing of brain injury, lead- 
ing to cerebral palsy, influences how genetic factors such as APOE impact reparative potential. If the APOE gene has a role in repair, it may be more effectively operative at a different point in the brain's development or with a different kind of injury than typically observed in preterm infants. Furthermore, there are regulator genes, which are possibly developmentally sensitive as well, that control APOE's expression. The search for genetic factors that predispose to cerebral palsy or affect its severity is important and could lead to novel preventive or therapeutic interventions. APOE does not appear to be related in a direct way to the developmental sequelae of white matter injury among extremely preterm infants.

\section{Acknowledgments}

This study was funded by the Eunice Shriver National Institute of Child Health and Human Development (R21HD058672, University of Virginia and R24HD050846, Children's National Medical Center) and by the University of Virginia Pratt and Children's Hospital Research Funds.

We wish to thank Amy Blackman and Jodi Darring for their assistance in the conduct of this study. Carol Long and Norma Dobbins administered the Bayley III Scales.

\section{References}

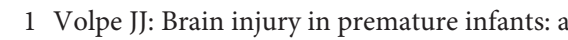
complex amalgam of destructive and developmental disturbances. Lancet Neurol 2009; 8:110-124.

2 Blackman JA, Worley G, Strittmatter WJ: Apolipoprotein E and brain injury: implications for children. Dev Med Child Neurol 2005;47:64-70

3 Blackman JA, Worley G, Conaway MR, Speer MC, Strittmatter WJ: Apolipoprotein E genotype and outcome after traumatic brain injury in children. Dev Med Child Neurol 2004; 46(suppl 100):26.
Blackman JA, Gurka MJ, Bao Y, Dragulev BP, Chen WM, Romness MJ: Apolipoprotein E and functional motor severity in cerebral palsy. J Pediatr Rehab Med 2009;2:67-74.

5 Woodward LJ, Anderson PJ, Austin NC, et al: Neonatal MRI to predict neurodevelopmental outcomes in preterm infants. N Eng J Med 2000;355:685-694.

6 Lien E, Andersen G, Bao Y, et al: Apolipoprotein E polymorphisms and severity of cerebral palsy: a cross-sectional study in 255 children in Norway. Dev Med Child Neurol 2013;55: 372-377.

-7 Bax M, Tydeman C, Flodmark O: Clinical and MRI correlates of cerebral palsy. JAMA 2008; 296:1602-1608. 